\title{
- Estudo citogenético de javalis puros (Sus Scrofa Scrofa) e híbridos nas regiões sudeste e sul do Brasil
}

\section{- Cytogenetic study of pure breed and hybrid wild boar (Sus Scrofa Scrofa) in Southeast and South Brazil.}

\author{
Jeffrey Frederico Lui - CRMV-SP $n^{0} 1870$ \\ 1 Professor Doutor do Departamento de \\ Zootecnia da FCAV - UNESP - Jaboticabal
}

\author{
Faculdade de Ciências Agrárias \\ e Veterinárias - UNESP \\ Departamento de Zootecnia, \\ Área de Genética Animal \\ Rodovia Prof. Paulo Donato \\ Castellane $\mathrm{s} / \mathrm{n}$ \\ Fone: (0XX16) 323-2500 \\ ramal 247 \\ e-mail: jeffrey@fcav.unesp.br
}

\section{RESUMO}

De dezembro de 1997 a março de 1999 foram realizadas análises citogenéticas em 1.137 javalis das regiões Sul e Sudeste do Brasil. Três grupos genéticos de animais foram identificados citogeneticamente: os com $2 n=36$, classificados como javalis puros, os com $2 n=37$, híbridos e os chamados "javaporcos" com $2 \mathrm{n}=38$, ploidia esta igual à do suíno doméstico. O javali, sendo uma subespécie como o suíno doméstico, tem facilidade neste cruzamento, permitindo assim o aparecimento de diferentes grupos genéticos nos criatórios onde não se tem controle reprodutivo adequado.

Palavras chave: Citogenética, javali, cromossomos, Sus scrofa scrofa.

\section{Introdução}

$\underline{0}$ javali está sendo criado devido à procura cada vez maior por sua carne. Esta é saborosa e com ótimas qualidades nutricionais, tais como, baixo teor de colesterol e de gordura. Como dados comparativos, tem-se na Tabela 1 os teores de proteína, gordura, calorias e colesterol encontrados em frangos, bovinos, javalis e suínos.

No Brasil, muitos criadores realizam o cruzamento de javalis com suínos, prática essa que tem resultado em perda da qualidade da carne, bastante diferente da do javali puro, além de lesar o consumidor que acaba pagando caro por um produto de qualidade inferior.

Os cruzamentos entre suínos domésticos $(2 \mathrm{n}=38)$ e javalis ( $2 n=36$ e 37$)$ com diferentes rearranjos cromossômicos podem ajudar a esclarecer a função genética dos cromossomos. BOSMA (1976) realizou estudo sobre polimorfismo cromossômico e padrão de banda $G$ em javalis (Sus scrofa) dos Países Baixos e encontrou resultados similares aos de TIKHONOV e TROSHINA (1975); TIKHONOV e TROSHINA (1978).

A maioria dos criadores de javalis no Brasil e em outros países desconhece o grau de pureza dos seus animais, pois, o javali, durante anos, tem-se cruzado com suínos domésticos, uma vez que o híbrido é um animal fértil (SYSA et al., 1984; TANCHEV e KATSAROV, 1993). Os híbridos podem reproduzirse com javalis puros ou mesmo com suínos domésticos cujas proles formadas são morfologicamente semelhantes às de javalis. Desse modo, esses animais acabam sendo criados como tal e destinados à comercialização. Com os cruzamentos, o número de cromossomos vai se distanciando do número próprio do javali $(2 \mathrm{n}=36)$, e a qualidade e sabor característi- 


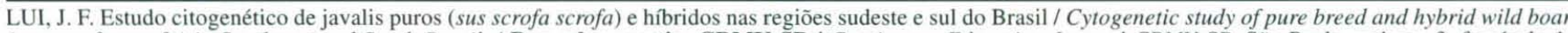

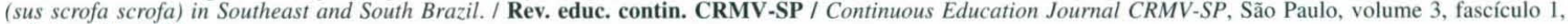
p. $043-048,2000$.

Tabela 1 - Teores comparativos de nutrientes entre o javali e três espécies animais.

\begin{tabular}{|c|c|c|c|c|}
\hline \multicolumn{5}{|c|}{ VALORES COMPARATIVOS DE NUTRIENTES (em 100 gr. de carne) } \\
\hline Tipo de Carne & Calorias & Gordura (g) & Proteínas (\%) & Colesterol(mg) \\
\hline Frango & 110 & 1.24 & 23.1 & 83 \\
\hline Bovino & 175 & 9.20 & 21.5 & 92 \\
\hline Javali & 122 & 3.33 & 21.5 & 45 \\
Suíno & 134 & 5.00 & 20.9 & 101 \\
\hline
\end{tabular}

Fonte: Agricultura de Manitoba - Canadá (Via Internet)

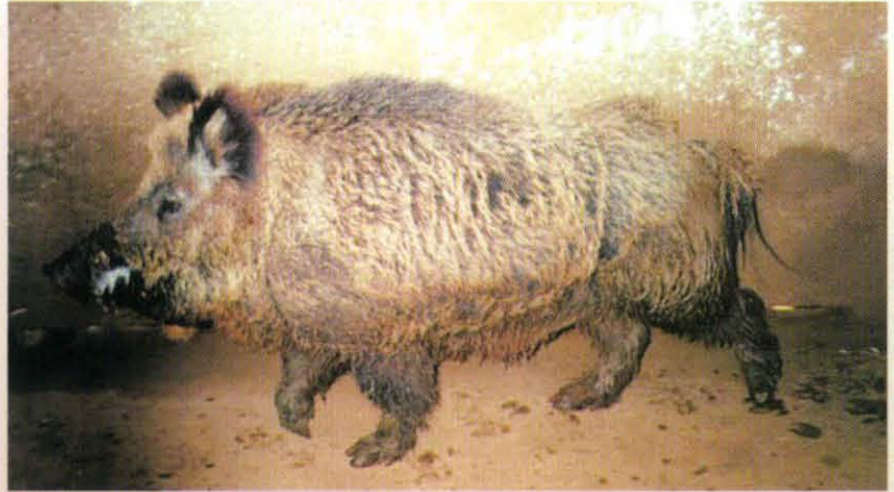

Figura 1: Reprodutor javali Sus scrofa scrofa, $2 \mathrm{n}=36$

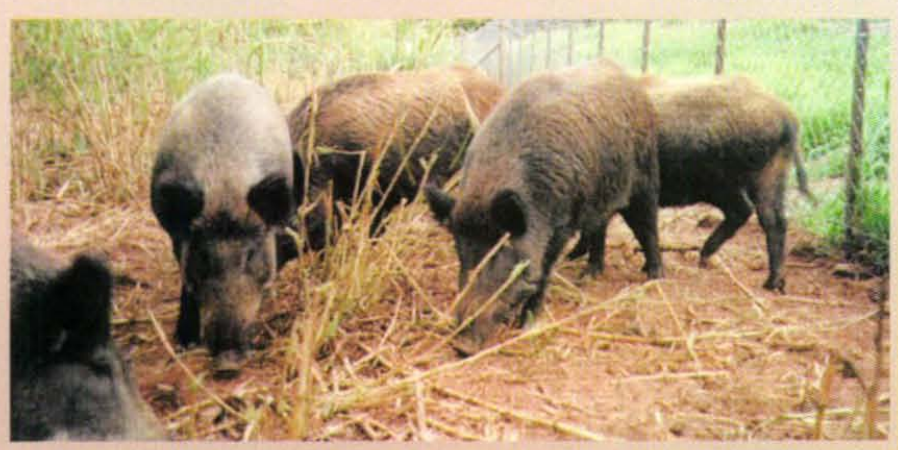

Figura 2: Javalis fêmeas (javalinas) Sus scrofa scrofa, $2 \mathrm{n}=36$

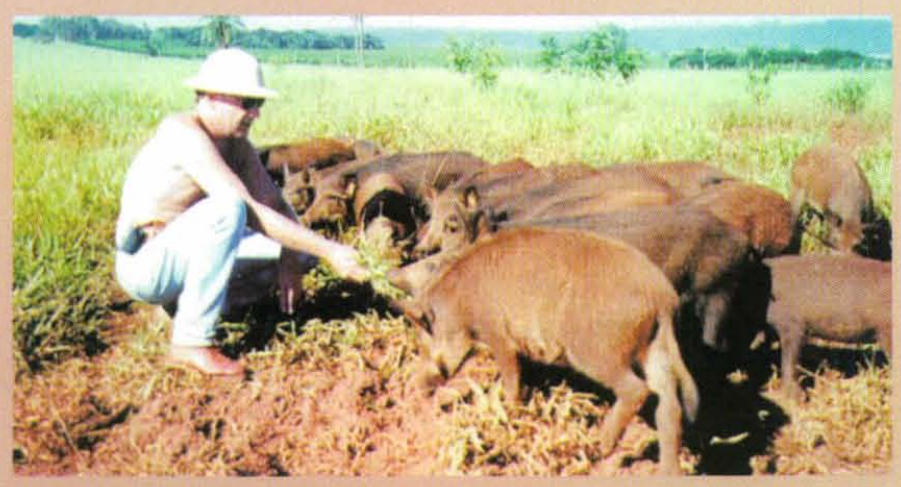

Figura 3: Javalis mestiços, domesticados, sendo criados como javalis puros co da carne provavelmente vai se alterando (RATIANI, 1990).

DARRÉ et al., (1992) pesquisaram populações de javalis para determinar sua categoria cromossômica em várias regiões da França. Esses autores encontraram uma freqüência alta, em torno de $90 \%$, de javalis com a ploidia de 36 cromossomos. O padrão com 36 cromossomos é considerado como critério para animais geneticamente puros. A proporção de javalis com 37 ou 38 cromossomos difere muito de acordo com a população e direção de acasalamento.

\section{Material e Métodos}

Cerca de 1.137 javalis de ambos os sexos provenientes dos Estados de Minas Gerais, São Paulo, Paraná, Santa Catarina e Rio Grande Sul foram cariotipados. A técnica de cultura baseouse na de MOORHEAD et al., (1960). Do material obtido foram confeccionadas lâminas para coloração Giemsa para análise, identificação e contagem dos cromossomos. Nas diferentes populações, foram separados os animais por grupos genéticos segundo a ploidia $(2 n=36,37$ e 38$)$. Os cálculos das frequiências em cada grupo, bem como por Estados da Federação nas duas regioes estudadas foram realizados. O estudos por meio de bandamento G (SCHERES, 1972) e C (SUMNER, 1972) permitiram a comprovação dos cromossomos envolvidos na fusão cêntrica.

As Figuras 1 e 2 mostram javalis puros machos e fêmeas com ploidia igual a 36 cromossomos e com características fenotípicas padrão para a raça. A Figura 3 apresenta "javaporcos" ou seja, resultado do cruzamento de javalis com suíno doméstico. 


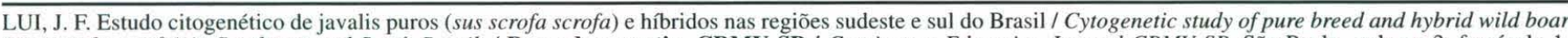

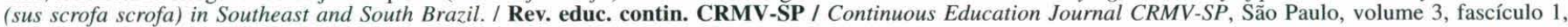
p. $043-048,2000$.

Tabela 2 - Distribuição das freqüências cariotípicas por Estado e grupo genético.

\begin{tabular}{|c|c|c|c|c|c|c|c|c|}
\hline \multicolumn{9}{|c|}{ VALORES COMPARATIVOS DE NUTRIENTES (em $100 \mathrm{~g}$ de carne) } \\
\hline \multirow[t]{2}{*}{ Estado Federativo } & \multirow{2}{*}{$\begin{array}{l}\text { Total de animais } \\
\text { cariotipados }\end{array}$} & \multicolumn{3}{|c|}{ "Puros" } & \multicolumn{2}{|c|}{ "Híbridos" } & \multicolumn{2}{|c|}{ "Javaporcos" } \\
\hline & & $2 n=$ & & $\%$ & $2 n=37$ & $\%$ & $2 n=38$ & $\%$ \\
\hline Rio Grande do Sul & 186 & 86 & & (46) & 67 & (36) & 33 & (18) \\
\hline Minas Gerais & 12 & 09 & & (75) & 03 & (25) & & \\
\hline Paraná & 02 & & 0 & & 01 & (50) & 01 & (50) \\
\hline Santa Catarina & 37 & 18 & & (49) & 16 & (43) & 03 & (8) \\
\hline São Paulo & 900 & 480 & & (53) & 313 & (35) & 107 & (12) \\
\hline Total & 1.137 & 593 & (52) & 400 & (35) & 144 & & \\
\hline
\end{tabular}

\section{Resultados e Discussão}

Dos 1.137 javalis estudados cariotipicamente, $52 \%$ eram de ploidia $2 \mathrm{n}=36,35 \% 2 \mathrm{n}=37$ e $12 \% 2 \mathrm{n}=38$. Os Estados de São Paulo e do Rio Grande do Sul foram os que apresentaram maior número de animais cariotipados, 900 e 186, respectivamente, seguidos dos de Santa Catarina e Minas Gerais.

A Tabela 2 apresenta a distribuição por Estado do número de javalis analisados, bem como a quantidade individual e a porcentagem em cada grupo.

Cerca de 48 propriedades com criação de javalis foram pesquisadas, das quais a maioria estava nos Estados de São Paulo (21) e Rio Grande do Sul (22). Neste último, as propriedades analisadas, com exceção de duas, eram pequenas e com poucos javalis, refletindo criações com pequena importância econômica e que apresentavam maiores índices de animais híbridos e "javaporcos".

O Estado de São Paulo, além de apresentar o maior número de animais cariotipados (900), mostrou uma frequiência maior de javalis com pureza cromossômica $(2 \mathrm{n}=36)$ que o Rio Grande do Sul, como pode ser observado na Tabela 2 e nos Gráficos 1 e 2.

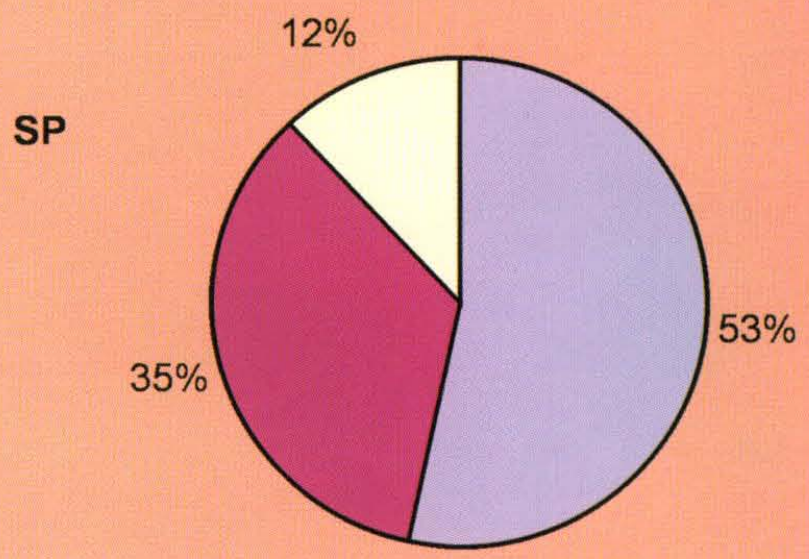

Gráfico 1 - Distribuição cariotípica de 900 javalis no Estado de São Paulo.

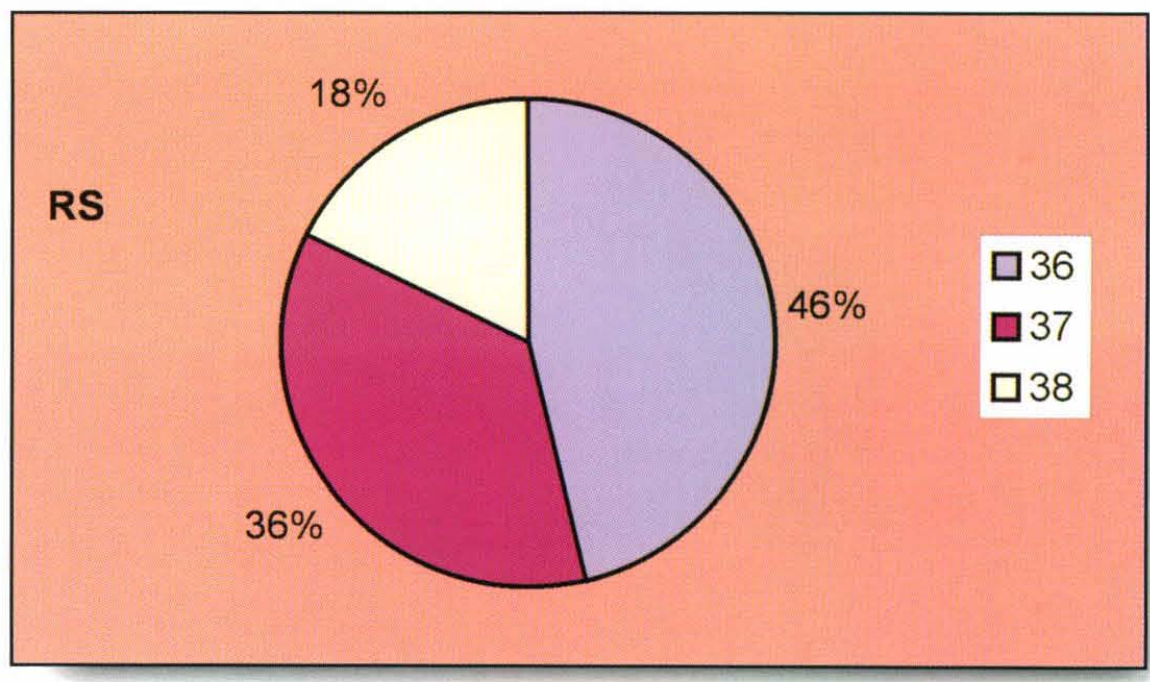

Gráfico 2 - Distribuição cariotípica de 186 javalis no Estado do Rio Grande do Sul.

De acordo com os resultados obtidos, pode-se verificar que há, ainda, muitos animais mestiços em ambos os Estados, mas no Rio Grande do Sul a freqüência é maior, apresentando inclusive valores maio- 


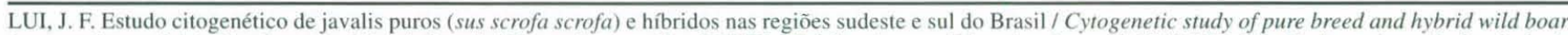

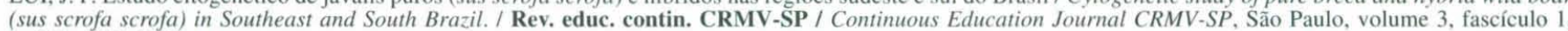
p. $043-048,2000$.

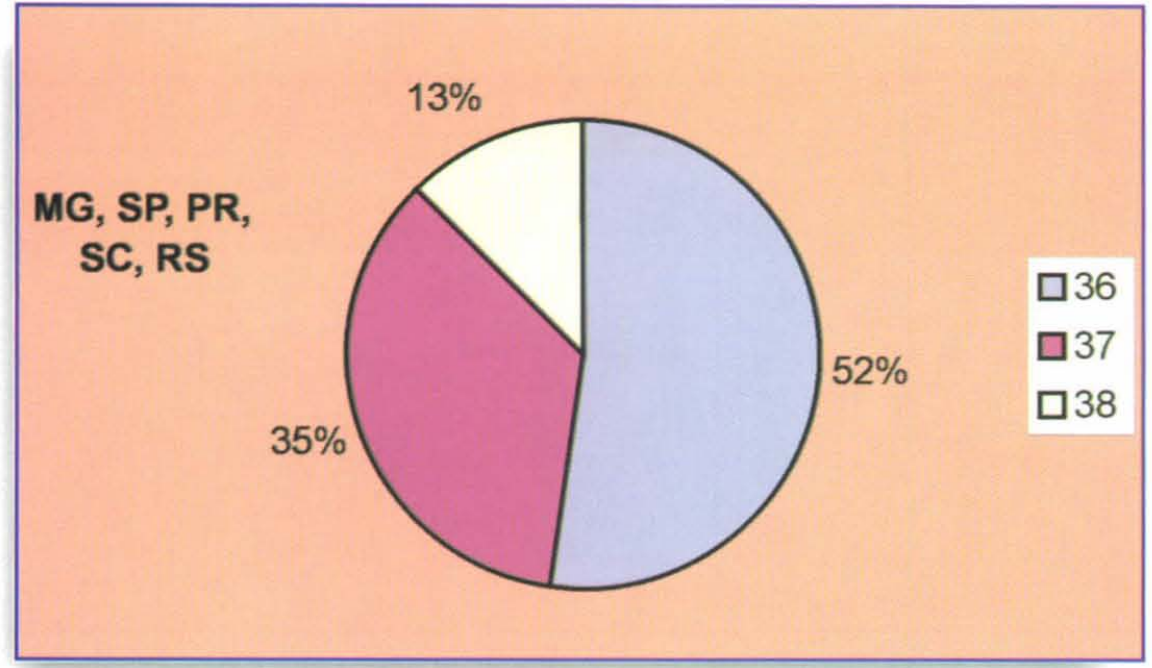

Gráfico 3 - Distribuição cariotípica de 1.137 javalis nas Regiões Sudeste e Sul do país.

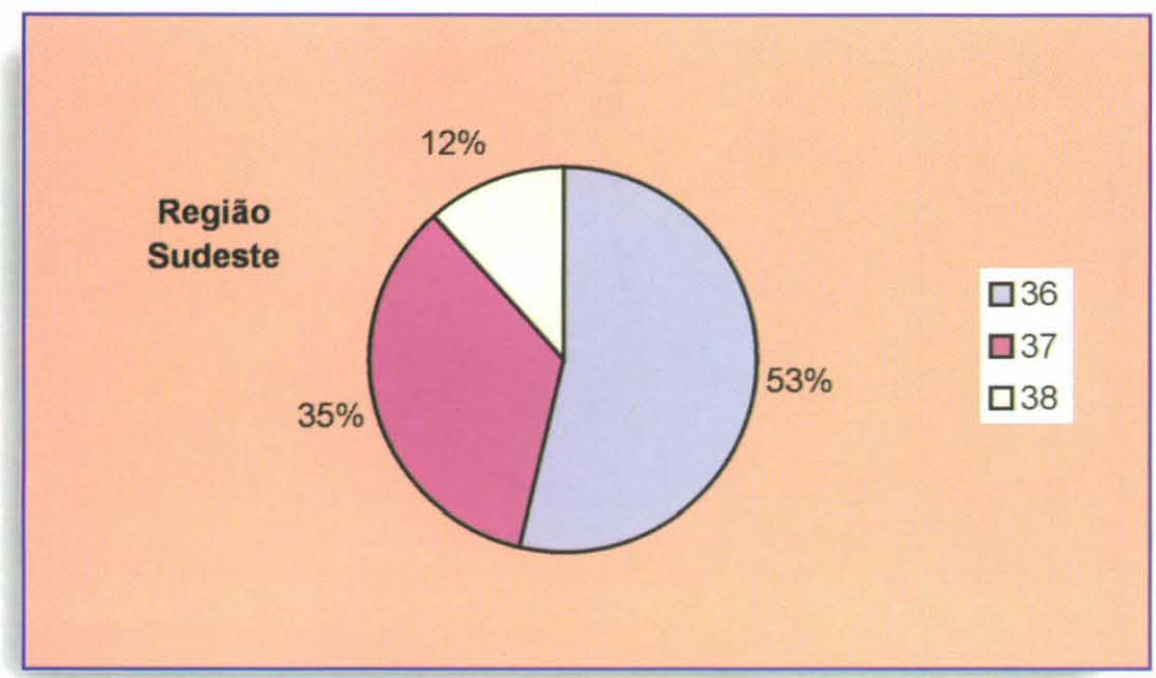

Gráfico 4 - Distribuição cariotípica de 912 javalis na Região Sudeste.

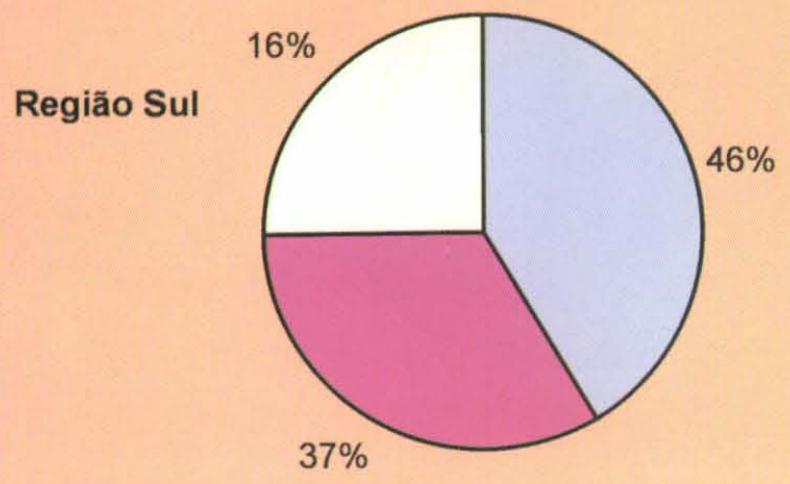

Gráfico 5 - Distribuição cariotípica de 225 javalis na Região Sul. res que os totais para as duas regiões estudadas, como pode ser verificado no Gráfico 3.

O Gráfico 4 representa a freqüência cariotípica de 912 javalis estudados somente na Região Sudeste. Os resultados são semelhantes àqueles totais das regiões e do Estado de São Paulo.

O Gráfico 5 representa a distribuição cariotípica dos javalis estudados na Região Sul. Pode-se notar claramente que há um aumento no número de animais híbridos "javaporcos" e, consequentemente, diminuição dos puros e híbridos verdadeiros.

O Gráfico 6 representa os três Estados (São Paulo, Rio Grande do Sul e Santa Catarina) que mais tiveram animais cariotipados e a distribuição das três diferentes ploidias. Pode-se notar que nos três Estados segue-se uma mesma tendência de distribuição das freqüências das ploidias nas populações examinadas, mas ressaltando-se que para o Estado de São Paulo há maior número de animais com $2 \mathrm{n}=36$ cromossomos.

A Figura 4 apresenta 4 cariótipos (representações A, B e C), dos quais 3 com bandamento $\mathrm{G}$ de javalis dos três grupos genéticos $(2 n=36,37$ e 38$)$, onde se pode ver os pares de cromossomos 15 e 17 envolvidos na fusão cêntrica e um cariótipo $(2 n=36)$ com bandamento C (representação D), onde a heterocromatina constitutiva está destacada, mostrando ainda que na fusão cêntrica os cromossomos são monocêntricos.

Os resultados obtidos permitiram concluir que existem muitos "javalis" sendo criados como animais puros mas que apresentam ploidia diferente da espécie.

Também indicam que há uma necessidade de realizar-se a cariotipagem do rebanho brasileiro, a fim de identificar-se os javalis verdadeiros dos híbridos para que haja uma purificação da raça e o consumidor possa adquirir produtos provenientes de javalis puros. 


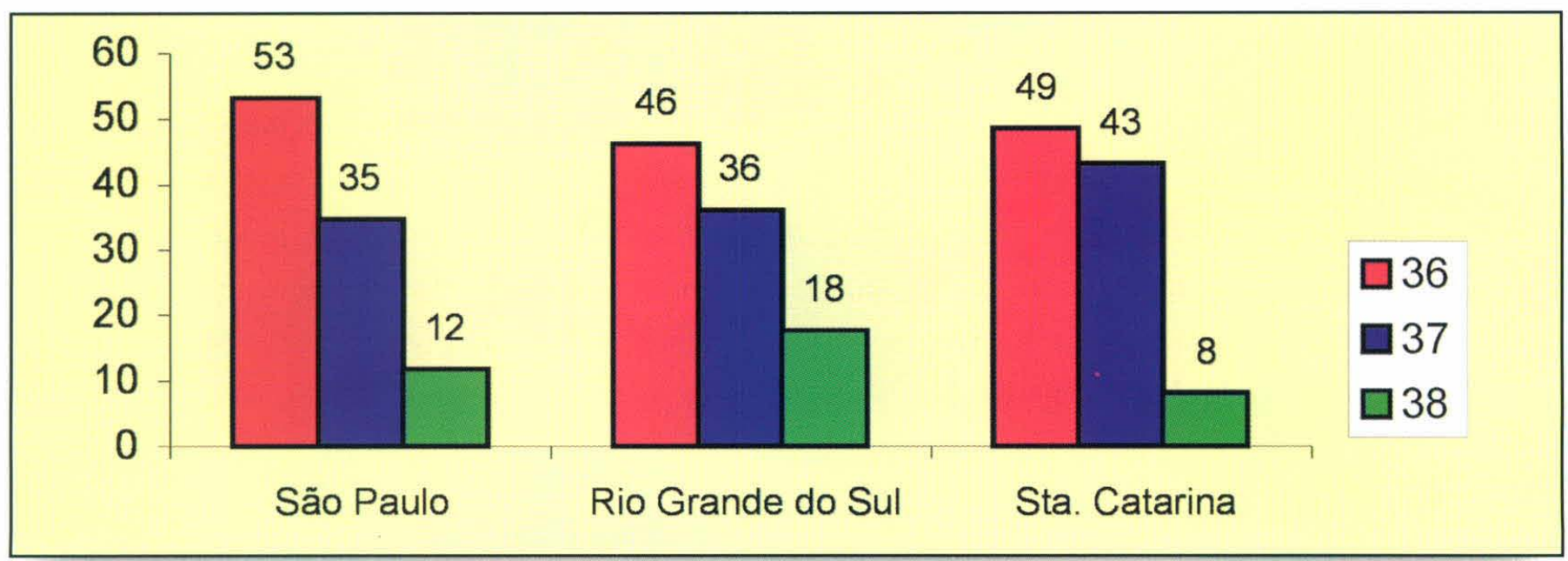

Gráfico 6 - Distribuição cariotípica em porcentagem nos três Estados estudados.

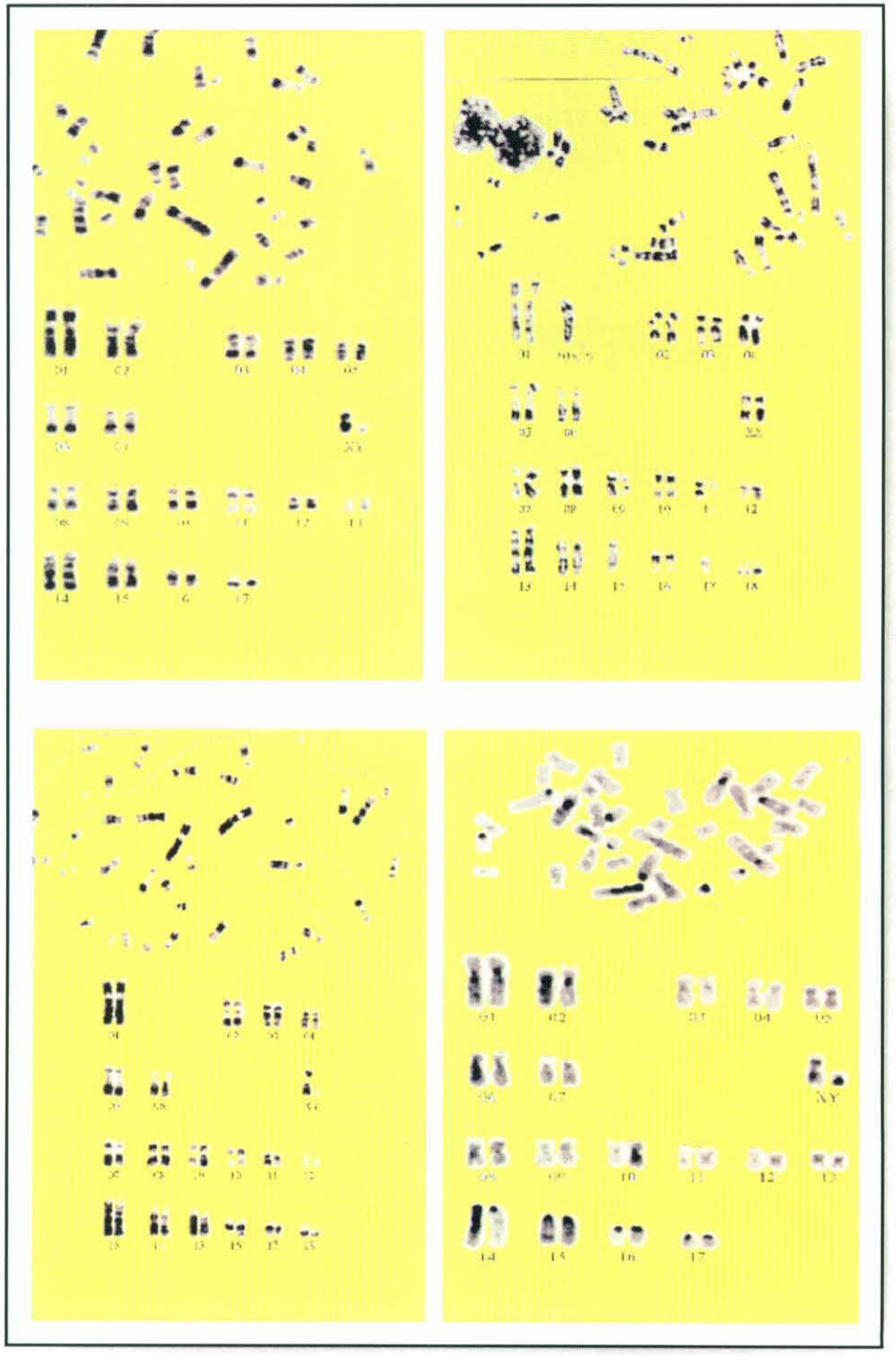

Figura 4: Cariótipos sob bandamento $\mathrm{G}$ (representações $\mathrm{A}$, $\mathrm{B}$ e C) e bandamento C (representação D), provenientes de javalis de três grupos genéticos 


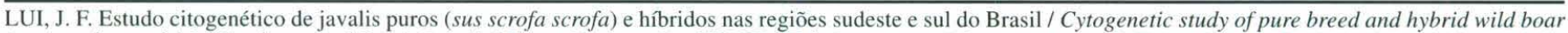

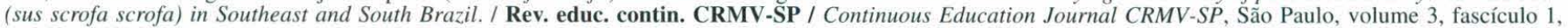
p. $043-048,2000$.

\section{SUMMARY}

From december of 1977 to March of 1999, cytogenetic analyses were carried out with 1,137 boars from South and Southeast areas of Brazil. Three genetic groups of animal were cytogenetically identified: a) $2 n=36$ classified as pure wild boars, b) $2 n=37$, hybrid and c) $2 n=38$, called "javaporco", ploidy which is equal to domestic pig. Being a subspecies as the domestic pig, the wild boars present facility in this breeding allowing the happening of different genetic groups in herd where the reproductive control is not appropriate.

Key words: Cytogenetic, wild boar, chromosomes, Sus scrofa scrofa.

\section{AGRADECIMENTOS}

"O autor agradece a todos que auxiliaram no presente trabalho, principalmente aos animais que "gentilmente" doaram seu material biológico para as análises".

\section{REFERÊNCIAS BIBLIOGRÁFICAS}

1 - BOSMA, A.A. Chromosomal polymorphism and G-banding patterns in the wild boar (Sus scrofa L.) from the Netherlands. Genetica, n.46, p.391-9, 1976.

2 - DARRÉ, R.; BERLANO, H.M.; GOUSTAT, P. Statut chromosomique des populations de sangliers sauvages et d'élevages en France. Revue Méd. Vét., v.143, n.3, p.225$32,1992$.

3 - MOORHEAD, P.S.; HOWELL, P.C.; MELLMAN, W.J. Chromosomes preparations leukocytes cultured from human peripheral blood. Exp. Cell. Res., v.20, p.613-6, 1960.

4 - RATIANI, D.P. On the problem of remote hybridisation of wild and domestic pigs. Soobshcheniya Akademii Nauk Gruzinskoi Ssr, v.138, n.2, p.377-80, 1990.

5 - SCHERES, J.M.J.C. Human chromosome banding. Lancet, v. 1, p. 849,1972 .

6 - SUMNER, A.T. A simple technique for demonstrating cen- tromeric heterochromatin. Exptl. Cell. Res., v.75, p.3046, 1972.

7 - SYSA, P.S.; SLAWOMIRSKI, J.; GROMADZKA, J. The cytogenetics of hybrids of the wild pig (Sus scrofa ferus) with the domestic pig (Sus scrofa domestica). Polskie Archiwum Weterynaryjne, v.24, n.1, p. 89 95, 1984.

8 - TANCHEV, S.; KATSAROV, V. Karyotype characterisation of hybrids between domestic and wild swine. Genetika I Selektsiya, v.26, n.3, p. 241-3, 1993.

9 - TIKHONOV, V.N.; TROSHINA, A. Chromosome translocations in the karyotypes of Wild Boars Sus scrofa of the European and the Asian Areas of USSR. Theor. Appl. Genet. v.45, p. 304-8, 1975.

10 - TIKHONOV, V.N.; TROSHINA, A. Introduction of two chromosomal translocations of Sus scrofa nigripes and Sus scrofa scrofa into the Genome of Sus scrofa domestica. Theor. Appl. Genet. v.53, p.261-4, 1978. 